\title{
ADAPTIVE PUSHOVER ANALYSES OF A HERITAGE STRUCTURE: APPLICATION TO A MULTI-TIERED PAGODA TEMPLE
}

\author{
YOHEI. ENDO ${ }^{1 *}$, YU. KONDO ${ }^{1}$, GAKU. IWANAMI ${ }^{1}$ \\ ${ }^{1}$ Shinshu University, 4-17-1, Wakasato, Nagano City 380-8553, Japan \\ e-mail: endii@shinshu-u.ac.jp
}

Keywords: Adaptive pushover analysis, Historical Structure, Masonry, Multi-tier pagoda, Seismic assessment

\begin{abstract}
The present paper discusses seismic behaviour of multi-tier pagoda temple. The seismic behaviour was examined by different pushover analysis techniques including adaptive pushover analysis. The case study objective is a five-tier pagoda. The studied pagoda is built of timber frameworks and masonry walls. Masonry is composed of burnt solid bricks and earthen mortar. The pushover analyses are conducted, taking into account frictional behaviour between timber and masonry.

The research challenges two tasks. A first task deals with experiments on interface behaviour between timber and masonry in earthen mortar. The study of the discussed interface behaviour is not straightforward since few tests have been conducted on similar subjects. In the present study, direct shear tests are performed. A second task coves pushover analyses of the five-tier pagoda by means of FE analysis. The paper provides useful experimental data of interface behaviour between timber and masonry in earthen mortar and also suggests efficient strategies of seismic assessment of pagoda-type structures.
\end{abstract}

\section{INTRODUCTION}

The paper presents nonlinear static analysis adopted to a multi-tier pagoda structure. Seismic behaviour of historical slender structures has been examined by researchers and practitioners. Among various seismic assessment tools, pushover analyses have been one of frequently used approaches [1]. Initial lateral force distribution patterns significantly influence the results such as maximum responses and damage mechanisms [2]. Recently advanced pushover analyses, including adaptive pushover analysis (APA) and multi-mode pushover analyses, were aimed to be adopted $[3,4]$. It has been found effective in some cases and however still the analyses encounter issues [5]. Further investigations are essential to apply APA more reliably.

The case study objective is a five-tier pagoda, Kumbeshwar temple in Nepal. The structure was seriously damaged by the 2015 Gorkha earthquake. The studied pagoda structure is composed of masonry walls and timber frameworks. The masonry is composed of solid bricks and earthen mortar. Sal timber is used for frameworks. Timber frameworks are considered to improve the box behaviour. On the other hand, limited experimental investigations have been conducted on interaction between timber elements and masonry walls $[6,7]$. The present research consists of two phases: experimental and numerical phase. The experimental phase examines interface behaviour between timber and masonry in earthen mortar by direct shear tests. The mechanical characterisation of the timber and masonry materials is conducted in advance of the direct shear tests. As for the numerical phase, taking into account the experimental results, different pushover analyses techniques are conducted on a pagoda structure. A particular attention is given on adaptive pushover analyses. The obtained results are compared with the damage patterns and collapse 
mechanisms observed in the real structure. The experiments suggest friction angle and cohesion of interface between timber and masonry in earthen mortar. The paper also aims to contribute to efficient and realistic approaches to the seismic assessment of historical slender structures including multi-tier pagoda type structures.

\section{RESEARCH METHODOLOGIES}

\subsection{Application of different pushover analysis techniques}

The present study compares three different seismic analysis methods. They are invariantforce pushover analysis (IPA), adaptive pushover analysis (APA), and nonlinear dynamic analysis (NDA). Comparison is made between IPA, APA and NDA in terms of horizontal base acceleration, displacement and damage patterns. As for IPA, two force distribution patterns were considered. One is proportional to the masses of the structure (m-IPA). The other is proportional to the shape of the fundamental mode of the structure ( $\Phi-I P A)$. As for APA, the method proposed by Antoniou and Pinho [8] is considered. In the method, the loading pattern at each step is incremented to that of the previous step. The load vector $P_{t}$ at a load step $t$ is achieved by adding to the load vector of the previous step $P_{t-1}$ (existing loads in equilibrium). The increment is calculated as the product between the current load factor increment $\lambda_{t}$, the current modal scaling vector $\bar{F}_{t}$ and the nominal load vector $P_{0}$, as presented in the equation (1).

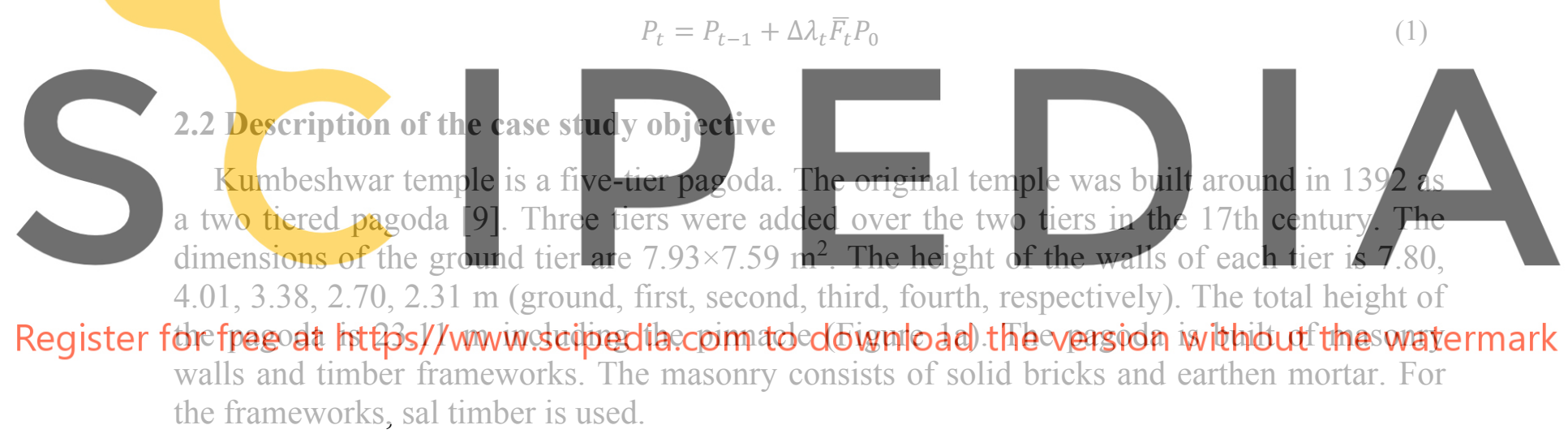

Kumbeshwar temple was severely damaged during the 2015 Gorkha earthquake. The fourth tier was considerably damaged but still survived. The collapse of the fourth tier occurred during the aftershock on May 12, 2015 (Figure 1b,c). The upper three tiers (second, third, fourth) were under reconstruction since they were much more significantly damaged than the lower tiers (first, second). In-situ visual inspection observed that pegs did not exist or lost in connections between timber crossbeams and masonry walls. Description and drawings of the temple are found also in $[10,11]$. 
(a)

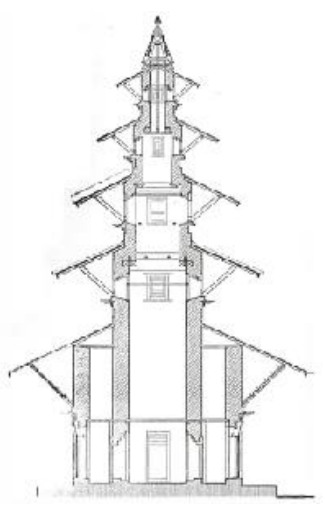

(b)

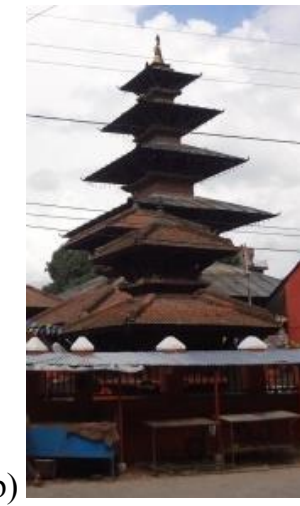

(c)

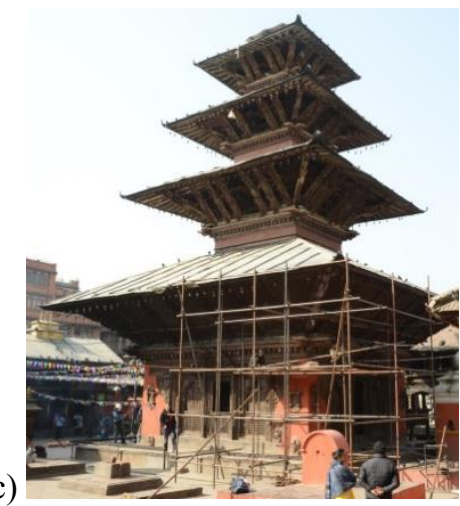

Figure 1: Kumbeshwar temple: (a) cross section [9], state before the 2015 Gorkha earthquake (b), after the 2015 Gorkha earthquake (c).

\section{EXPERIMENTAL STUDIES}

\subsection{Characterisation tests of masonry materials}

Uniaxial compression tests were conducted on bricks in accordance with European standards [12]. The tested bricks were chosen since they had similar surface texture and close density as those used for the studied pagoda. The bulk density was $1,750 \mathrm{~kg} / \mathrm{m}^{3}$. The dimensions of the tested prisms were $40 \times 40 \times 80 \mathrm{~mm}^{3}$. A $300-\mathrm{kN}$ autograph testing machine was used for the loading [13]. The same testing machine was used for all the tests discussed

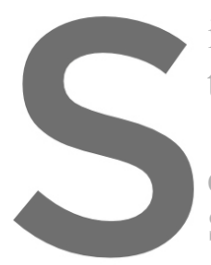
in the paper. The avdrage compressive strength was 17.8 MPa. the prisms was $1.08[12$ Loam was used for the preparation conducted on the loam by a hydrometer mothod according tr Society [14]. The grain (sand, silt, clay) were $26.2 \%, 52.2 \%, 21.6 \%$ by weight.

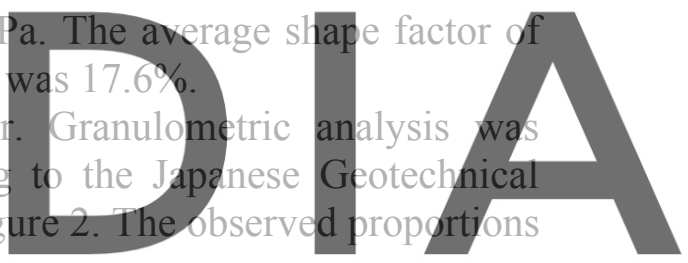

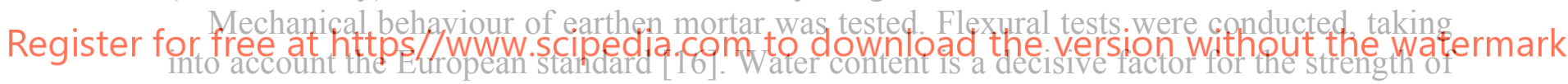
earthen mortar [17]. In the tested cases, the water content was set to measure $15.0 \mathrm{~cm}$ by a flow-table test. The dimensions of the prisms were $40 \times 40 \times 160 \mathrm{~mm}^{3}$. The prisms were cured for 56 days. The volumetric shrinkage was $20.3 \%$. Three-point bending tests were conducted. The average flexural strength was $1.35 \mathrm{MPa}$. COV was $15.20 \%$. The maximum flexural strain was $1.22 \%$. The flexural module at $1 / 3$ of the peak strength was $0.18 \mathrm{GPa}$ in average. Immediately after the bending tests, uniaxial compression tests were carried out on the same prisms. In total, 12 prisms were tested. The compressive strength was $3.82 \mathrm{MPa}$ in average. COV was $13.82 \%$. 


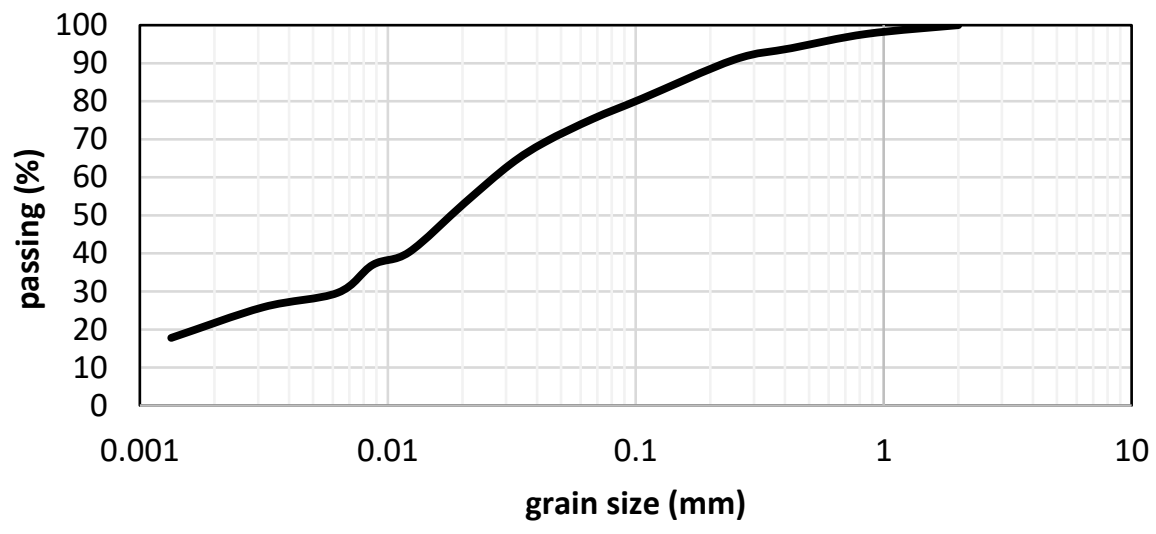

Figure 2: Grain size distribution curve.

\subsection{Mechanical characterisation tests of sal timber}

Mechanical behaviour of sal timber was conducted, referring to the Japanese standard [18]. Two types of tests were conducted as follows: uniaxial compression tests parallel and perpendicular to the grain and three-point bending tests. The uniaxial compression tests were performed on prisms of $30 \times 30 \times 60 \mathrm{~mm}^{2}$. The three-point bending tests were carried out on prisms of $30 \times 30 \times 420 \mathrm{~mm}^{3}$. The prisms were $836 \mathrm{~kg} / \mathrm{m}^{3}$ in bulk density.

The average compressive strength of two types $\left(\mathrm{f}_{\mathrm{c}, 0}, \mathrm{f}_{\mathrm{c}, 90}\right)$ were $55.1 \mathrm{MPa}$ and $13.3 \mathrm{MPa}$. COV was $8.23 \%$ and $5.86 \%$. The maximum strain was $\left(\varepsilon_{c, 0}, \varepsilon_{c}, 90\right) 2.16 \%$ and $9.29 \%$. The

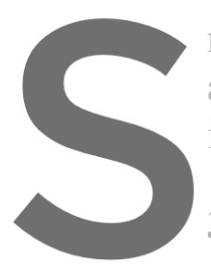
modulus of elasticity at average flexural streng in average. The average

3.3 Direct shear tests
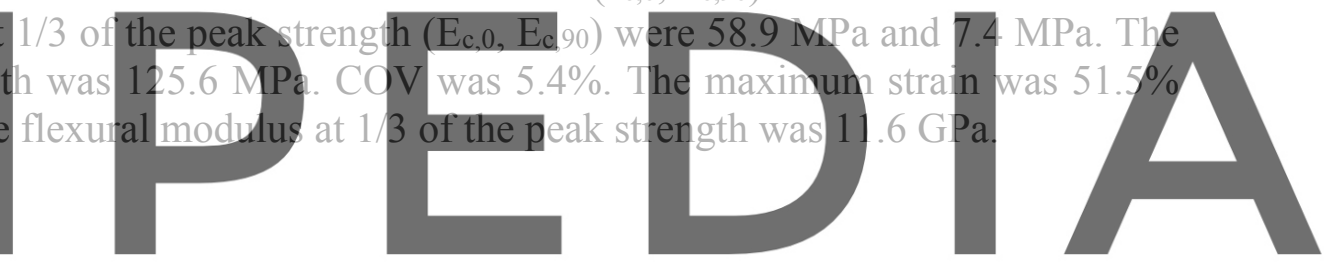

Direct shear tests were performed to examine frictional behaviour between sal timber and

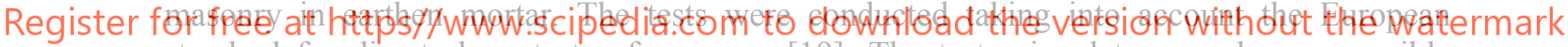
standard for direct shear tests of masonry [19]. The tests aimed to reproduce a possible situation of connections between timber crossbeams and masonry walls of multi-tier pagodas.

Thus, it is considered possible that connections between cross beams and walls rely only on friction between two structural elements as discussed in Section 2.2.

The triplet specimens were prepared. The used bricks and sal timber were those tested as discussed in Section 3.1, 3.2. In the middle portion of the specimen, a timber block was placed (Figure 3a). The dimensions of the timber blocks were the same as the bricks. The dimensions of the bricks were $50 \times 85 \times 185 \mathrm{~mm}^{3}$. The thickness of the joint was $10 \mathrm{~mm}$. Three different conditions of pre-compressive stress were considered (0.2 $\mathrm{MPa}, 0.6 \mathrm{MPa}, 1.0 \mathrm{MPa})$. Three specimens were tested in each condition of the pre-compressive stress. The stress was provided by the jig composed of two steel plates and four steel bolts (see, Figure 3a). One plate was placed at the top of the specimen while the other at the bottom. The steel plates were connected by the four bolts. The value of pre-compressive stress was confirmed by measuring the torque of the nuts. It is noted that the dilatancy of the specimen was considered negligible since the sliding of the timber block occurred at a very low value of the loading.

The average observed shear strength was $0.07,0.2,0.33 \mathrm{MPa}$ respectively. All the tested specimens showed shear failure in the mortar bond area on the timber face (Figure $3 b$ ). 
(a)

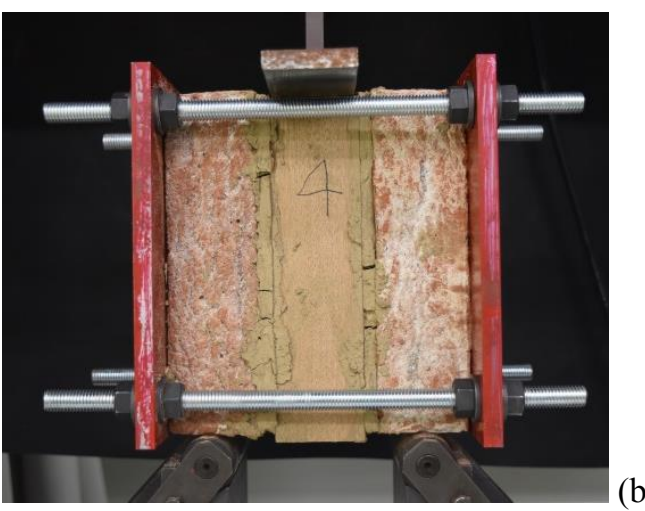

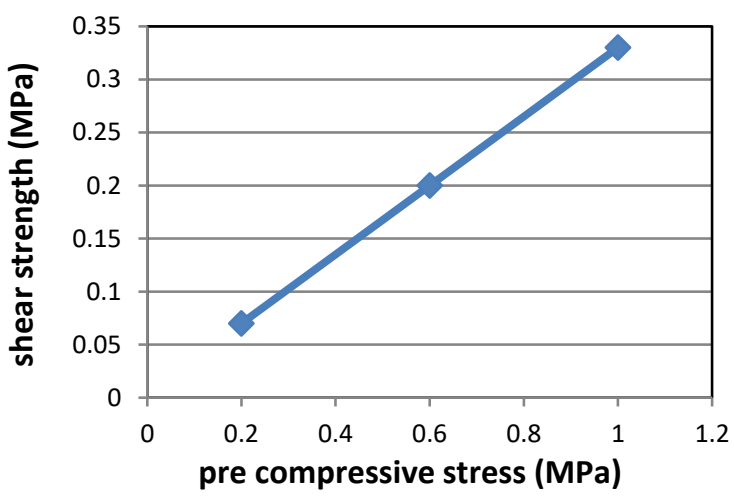

pre compressive stress ( $\mathrm{MPa})$

Figure 3: Initial shear strength test: (a) failure of a specimen and (b) normal and shear stress relation.

\section{PUSHOVER ANALYSES}

\subsection{Material models}

The considered material parameters for the present study are shown in Table 1. The parameters of the timber were determined, considering the Nepalese building code (NBC) [20] and charaeterisation tests discussed in Section 3.2. The parameters of the brick masonry were chosen in accordance with the previously conducted masonry material characterisation tests [21] and NBC [15]. Empirical equations were also taken into account $[22,23]$. To determine the material parameters, sensitivity analyses were carefully performed. Two types of

inasonry were conside in Section 2.2. They masonry of limited strength. The compressive of $\mathrm{fc}$. The modulus of elasticity is 150 times $\mathrm{f}$. strength. The compressive strength is $3.2 \mathrm{MPa}$
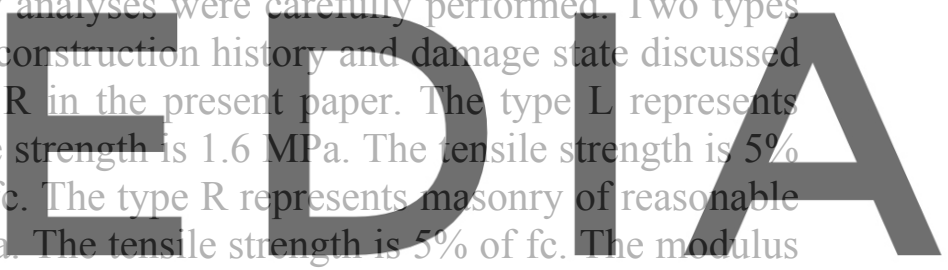
of elasticity is 250 times fc. The masonry walls of the upper three tiers (second, third, fourth)

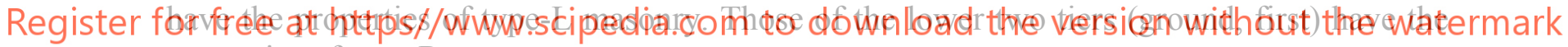
properties of type-R masonry.

As for the failure criteria, the von Mises plasticity model was adopted to the timber in compression and tension. The smeared crack model was adopted to the brick masonry. Drucker-Prager criterion was considered in compression while Rankin criterion in tension. A linear softening curve was considered in tension for uniaxial behaviour. The fracture energy was set as $25 \mathrm{~N} / \mathrm{m}$ for the masonry type L ( $50 \mathrm{~N} / \mathrm{m}$ for type R) in tension.

Interface behaviour was considered between the timber cross beams and masonry walls. The considered interface behaviour was determined in accordance with the tests discussed in Section 3.2. The Mohr Coulomb friction model was adopted. For the normal linear stiffness, $100 \mathrm{~N} / \mathrm{mm}^{3}$ was considered and $50 \mathrm{~N} / \mathrm{mm}^{3}$ for the shear linear stiffness. The considered friction angle was $18.9^{\circ}(\tan \phi=0.33)$. The value of the tensile strength of the masonry was considered as the value of cohesion. Both geometrical and material nonlinearity were adopted. 
Table 1: Adopted material parameters

\begin{tabular}{cccc}
\hline & $\begin{array}{c}\text { brick masonry } \\
\text { (type A) }\end{array}$ & $\begin{array}{c}\text { brick masonry } \\
\text { (type B) }\end{array}$ & timber \\
\hline Modulus of elasticity (GPa) & 0.4 & 0.8 & 15 \\
\hline Tensile strength (MPa) & 0.08 & 0.16 & 40 \\
\hline Compressive strength (MPa) & 1.6 & 3.2 & 40 \\
\hline Poisson ratio (-) & 0.2 & 0.2 & 0.3 \\
\hline Unit weight $\left(\mathbf{k g} / \mathbf{m}^{\mathbf{3}}\right)$ & 1,800 & 1,800 & 900 \\
\hline
\end{tabular}

\subsection{Description of the FE models}

The FE model was created in the software of TNO DIANA [24]. The model is composed of 29,563 nodes, 18,579 eight-node brick solid elements, 2,893 two-node beam elements, 253 four-node shell elements, 64 eight-node shell interface elements and 2,883 mass elements (Figure 4a). The solid elements were used for the masonry walls. The beam elements were for the timber columns and roof members. The shell elements are for timber cross beams. The mass elements were positioned on the beam elements representing the roof rafters as the dead weight of the ceramic tiles, mud and corrugated steel. The timber doors and window panels were not discretised in the model. As for the roof, the timber rafters, joists and beams were only discretised. Taking advantage of the symmetry of the structure, a half model is used. The cross sections of the model were translationally constrained in the $\mathrm{Y}$ direction and rotationally constrained around the $\mathrm{X}$ and $\mathrm{Z}$ direction. The model is fully constrained along

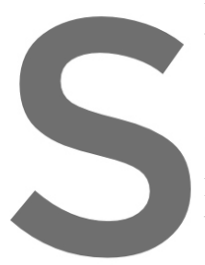
the bottom of the structure.

The analyses were connections between tir named the rigid connection between timber crossbe adopted to two mo
mber crossbeans and
tion model (RiC model)
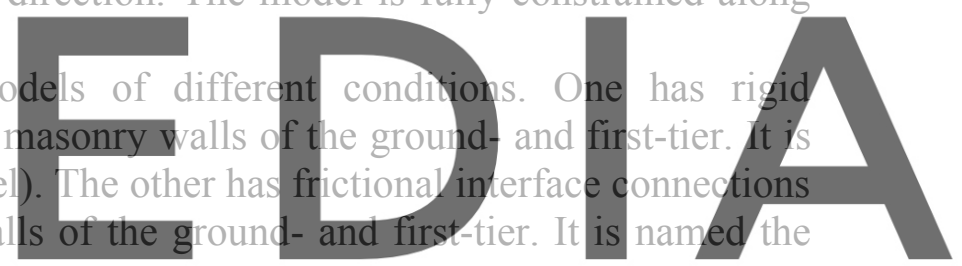
frictional interface model (FI model).

Register for free at https//www.scipedia.com to download the version without the watermark

(a)

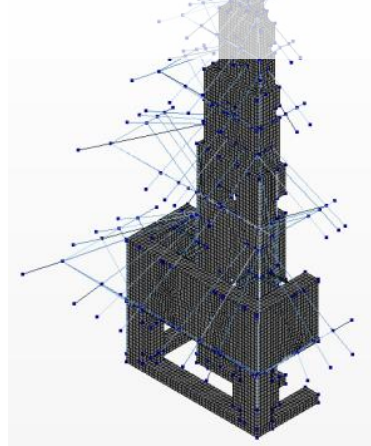

(b)

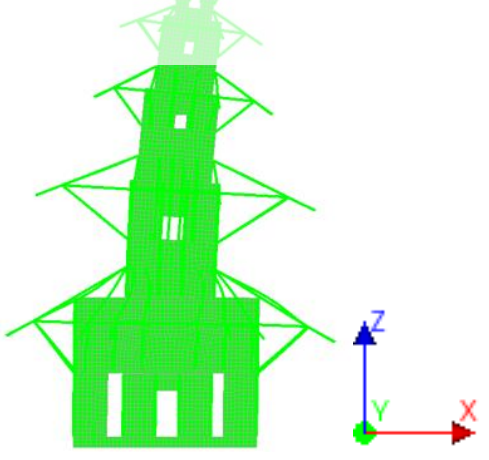

Figure 4: FE model of Kumbeshwar temple: (a) half model and (b) fundamental mode shape.

\subsection{Application of invariant-force pushover analyses}

Two types of IPA (m-IPA, $\Phi$-IPA) were adopted to the half model of Kumbeshwar temple. Figure $3 \mathrm{~b}$ shows the shape of the fundamental mode considered for the lateral force distribution patterns of $\Phi$-IPA. As for m-IPA of RiC model, the maximum horizontal base acceleration was equal to $0.227 \mathrm{~g}$. The corresponding displacement was $4.19 \mathrm{~mm}, 14.05 \mathrm{~mm}$, $33.9 \mathrm{~mm}$ at the top of the ground-, first- and fourth tier, in turn (Figure 5a-c). Damage of the ground tier indicated out-of-plane movement of the transversal walls and in-plane movement 
of the longitudinal walls over the entrance opening (Figure 6a). Damage patterns in the first tier suggest out-of-plane movement of transversal walls. FI model showed lower values of horizontal base acceleration and displacement than RiC model. The observed maximum displacement values were $4.19 \mathrm{~mm}, 14.0 \mathrm{~mm}, 34.0 \mathrm{~mm}$ at the top of the ground-, first- and fourth tier. The maximum horizontal base acceleration was $0.228 \mathrm{~g}$. Both $\mathrm{RiC}$ and FI model showed similar damage patterns in the ground- and first-tier in spite of the difference of damage intensity. However, only $\mathrm{RiC}$ model presented damage in the third tier (Figure 6b).

As for $\Phi$-IPA of RiC model, the maximum horizontal base acceleration was $0.093 \mathrm{~g}$. The observed maximum displacement values were $1.84 \mathrm{~mm}, 12.5 \mathrm{~mm}, 67.1 \mathrm{~mm}$ at the top of the ground-, first- and fourth tier. Figure 6c shows damage patterns along the corner of ground and first tier due to out-of-plane movement. In-plane damage was also seen in the second and third tier. Regarding FI model, the maximum horizontal base acceleration was $0.088 \mathrm{~g}$. The observed maximum displacement values were $1.57 \mathrm{~mm}, 11.3 \mathrm{~mm}, 45.6 \mathrm{~mm}$ at the top of the ground-, first- and fourth tier. FI model showed damage patterns similar to RiC model although FI model showed lower damage severity (Figure 6d).

Influences of interface behaviour are discussed by comparing the results between $\mathrm{RiC}$ and FI model. RiC model presented higher horizontal base acceleration and displacement than FI model by m-IPA and $\Phi$-IPA. Nonetheless, RiC and FI model showed similar damage patterns although RiC model presented much severe damage than FI model.

The observed damage patterns were slightly different between m-IPA and $\Phi$-IPA. As for FI model, $\Phi$-IPA showed damage concentrated in the second tier in addition to the damage in the corner of the ground- and first-tier. On the other hand, m-IPA showed damage only in the

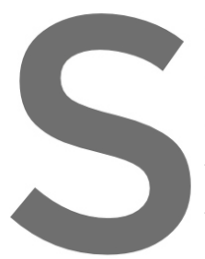
corner of the groundof lateral load distribution concentration in the uppostion the ground tier presented clos that the lateral force dis
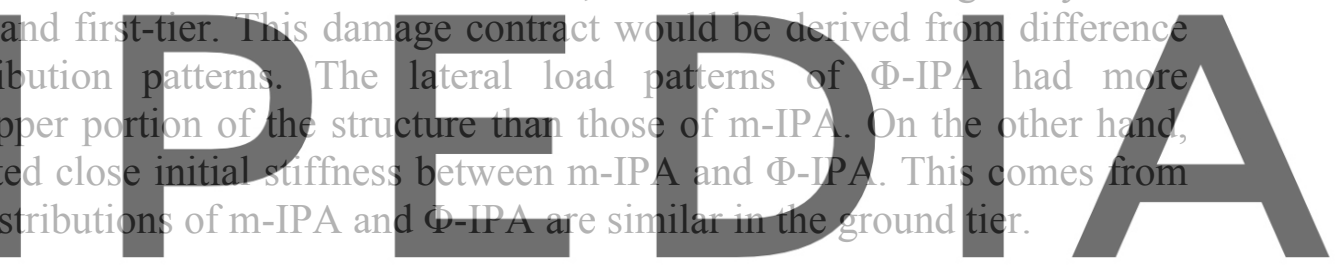

Register for free at https//www.scipedia.com to download the version without the watermark 
(a)
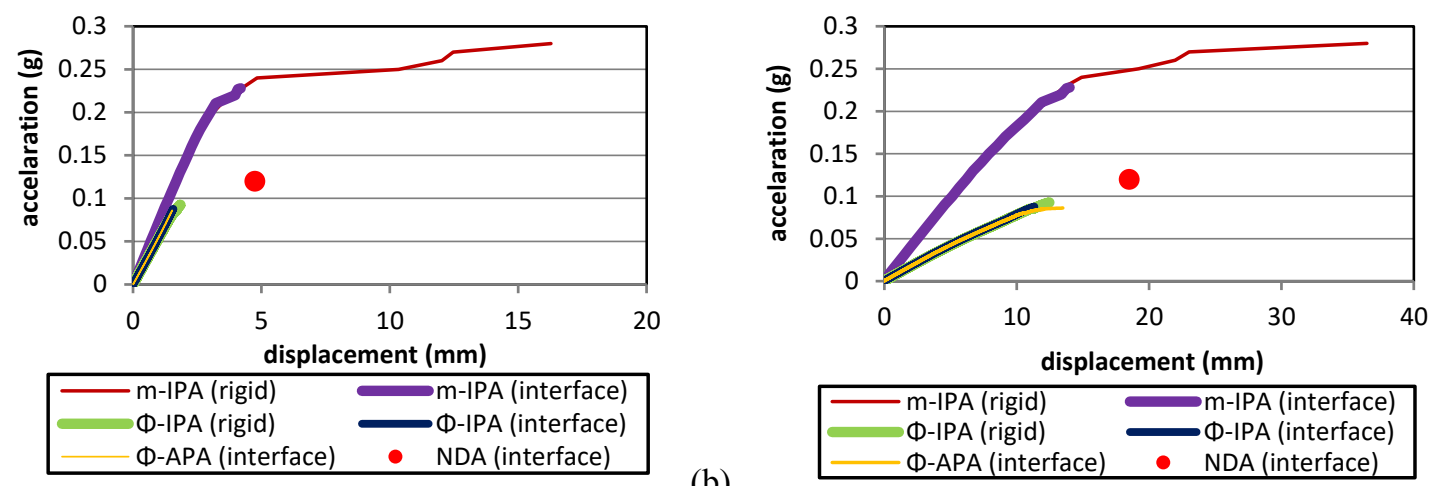

(b)
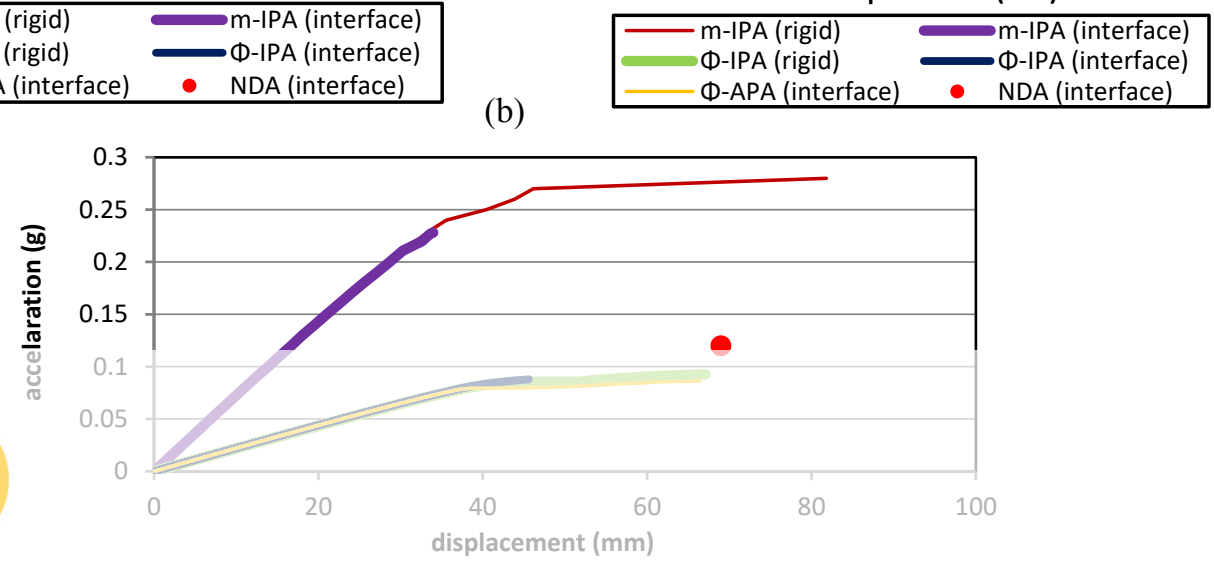

(c) \begin{tabular}{lll|}
\hline$\longrightarrow$ m-IPA (rigid) & D-IPA (interface) & DPA (rigid) \\
D-IPA (interface) & Ф-APA (interface) & NDA (interface) \\
\hline
\end{tabular}

Figure 5: Seismic analy
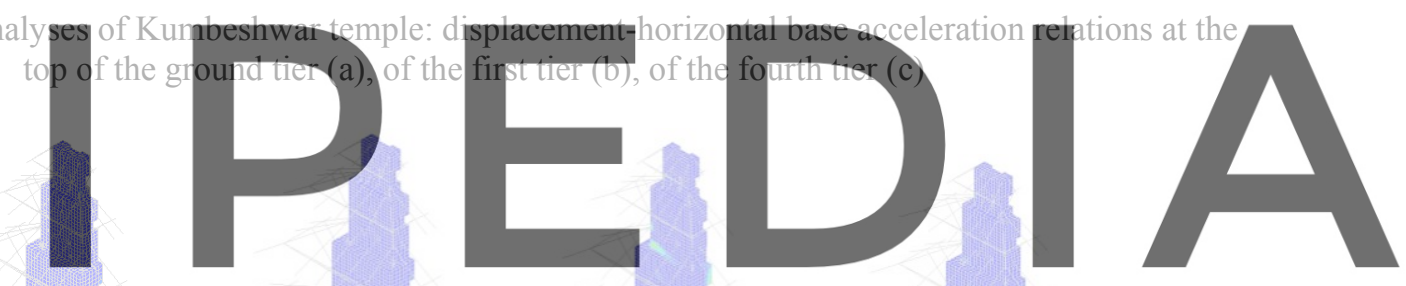

Register for free at https//www.scipedia.com to download the version without the watermark

(a)

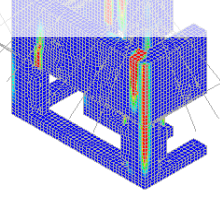

(b)

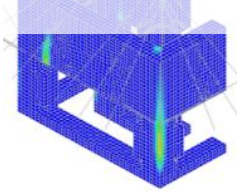

(b)

(c)
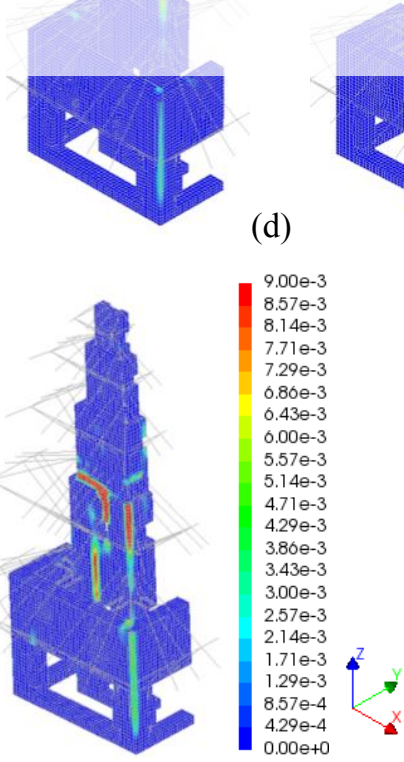

(e)

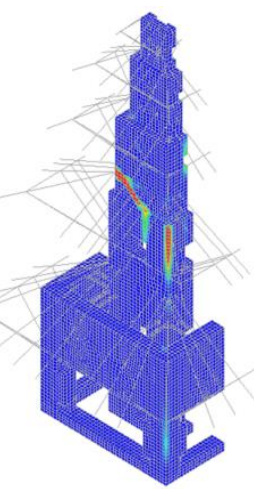

(f) (d)

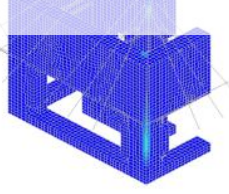

Figure 6: Tensile strain distributions close to the ultimate state: m-IPA of RiC model (a), of FI model (b), of $\Phi$ IPA of RiC model (c), of FI model (d), APA of FI model (e) and NDA of FI model (f). 


\subsection{Application of adaptive pushover analysis}

APA was applied to FI model. The initial lateral load patterns $\left(P_{0}\right)$ were the shape of the fundamental mode of the structure (Figure $4 \mathrm{~b}$ ). The maximum horizontal base acceleration was $0.086 \mathrm{~g}$. The corresponding displacement values were $1.5 \mathrm{~mm}$ at the top of the ground tier, $13.5 \mathrm{~mm}$ at the top of the first tier and $66.5 \mathrm{~mm}$ at the top of the fourth tier (Figure 5a-c). The model showed vertical damage in the corner of the ground- and first-tier (Figure 6e). In-plane damage was also observed in the second tier.

APA presented horizontal base acceleration-displacement relations similar to $\Phi$-IPA. However, the observed damage patterns were noticeably different (see Figure 6d,e). APA showed slightly lower initial stiffness than $\Phi$-IPA from the beginning of the application of the lateral forces. It is due to damage caused by dead load. Since the model had limited strength as presented in Section3.1, certain damage already appeared during the application of gravity to the model. It ended in a slight change of the initial stiffness between $\Phi$-IPA and APA.

NDA was adopted to FI model. NDA of Kumbeshwar temple was originally presented in a previously published conference paper [10]. In the present study, NDA was performed on the model presented in Section 4.1, 4.2. The maximum horizontal base acceleration was $0.120 \mathrm{~g}$. The observed maximum displacement values were $4.7 \mathrm{~mm}, 18.5 \mathrm{~mm}, 69.0 \mathrm{~mm}$. APA and NDA showed vertical damage along the window opening in the first tier (see Figure 6e,f). However, the vertical damage was much extensive in NDA than APA. NDA showed horizontal damage around the base of the second tier. Instead, APA presented diagonal damage in the second tier. The difference of the damage in the second tier would come from 5 CONCLUSIONS
Direct shear tests were conducted to examine friction angle and cohesion of interface
between timber and inasonry in earthen mortar. The tests presented reasonable friction angle

for such interface and nearly zero cohesion as expected. The tests were performed, taking into

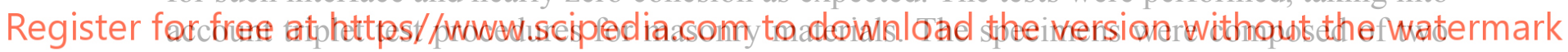
bricks and a timber block in the middle. As further experimental activities, larger-scale specimens will be tested to examine interface behaviour more closely.

In the present study, pushover analyses were carried out on the models with and without frictional behaviour between timber cross beams and masonry walls. Adoption of fictional behaviour avoided overestimation of the capacity of the studied pagoda. However, the conducted pushover analyses implied interface behaviour had to be carefully included in models since the results were unignorably influenced by interface behaviour.

The studied pagoda showed damage due to in-plane and out-of-plane movement. Vulnerabilities to in-plane movement were derived from large openings while vulnerabilities to out-of-plane movement due to limited tensile strength. In the study, the load patterns of APA were the shape of the fundamental mode. APA provided results closer to NDA than IPA in terms of damage distribution patterns. However, it was found that the application of APA was a time-consuming process. Eigenvalue analysis had to be run and load distribution patterns were updated manually at each step accordingly. The initial lateral load patterns were found to be a predominant factor to the analysis results. For the further research of APA, different initial load patterns and updating methods will be studied. In addition for close observations of results between pushover analyses and NDA, the application of N2 method will be considered. 
Acknowledgements. The authors would like to acknowledge the Maeda engineering foundation for providing us with the funds for the present research.

\section{REFERENCES}

[1] Pelà, L., Alessandra A. and Benedetti, A. "Seismic assessment of masonry arch bridges." Engineering Structures 31, no. 8 (2009): 1777-1788.

[2] Lagomarsino, S. and Cattari, S. "Seismic performance of historical masonry structures through pushover and nonlinear dynamic analyses." In Perspectives on European earthquake engineering and seismology. Springer, Cham (2015): 265-292.

[3] Facchini, L., Betti M., Corazzi, R. and Vladimir, C.K. "Nonlinear seismic behavior of historical masonry towers by means of different numerical models." Procedia engineering 199 (2017): 601-606.

[4] Ferraioli, M., Miccoil L., Donato, A.D. and Mandara, A. "Dynamic characterisation and seismic assessment of medieval masonry towers." Natural Hazards 86, no.2 (2017): 489515.

[5] Endo, Y., Pelà, L. and Roca, P. "Review of different pushover analysis methods applied to masonry buildings and comparison with nonlinear dynamic analysis." Journal of Earthquake Engineering 21, no.8 (2017): 1234-1255.

[6] Moreira, S., Ramos, L.F., Oliveira, D.V., and Lourenço, P.B. "Experimental behavior of masonry wall-to-timber elements connections strengthened with injection anchors."

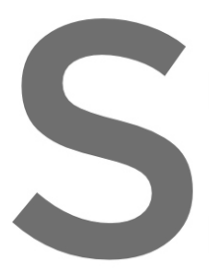
Engineering structu

7] Vieux-Champagne, L. "Experimental and earth infill." teng Antoniou, S. and Pinho, R.
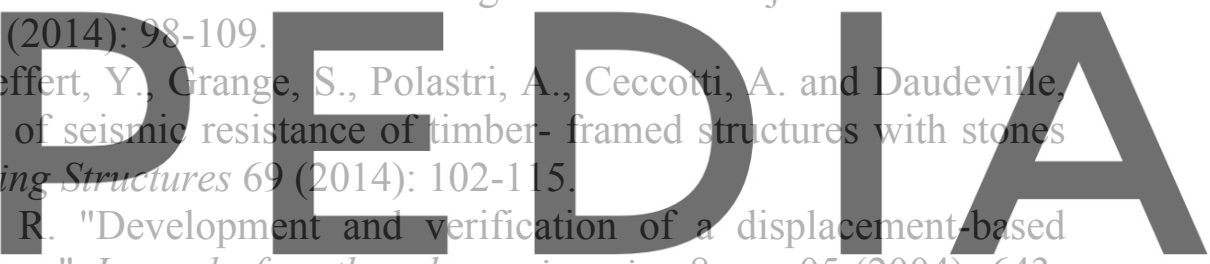
adaptive pushover procedure." Journal of earthquake engineering 8, no. 05 (2004): 643-

Register for free at https//wwws.scipedia.com to downlaad the versign without the watermark Nutshell" With Some Comparative Traces of Foreign History. Vol. 1. (1972)

[10] Center for Applied Research and Development (CARD) Measured drawing of Kumbeshwar temple. Institute of Engineering, Pulchowk Lalitpur (2009).

[11] Endo, Y. and Hanazato, T. "Seismic Behaviour of a Historic Five-Tiered Pagoda in Nepal." In Structural Analysis of Historical Constructions. Springer, Cham, (2019): 1337-1345.

[12] European Committee of Standardization (CEN), EN772-1, Methods of Test for Masonry Units-Part 1: Determination of Compressive Strength, CEN, Brussels, 2011.

[13] Shimadzu Corporation. "Autograph AGS-X Series" Shimadzu Corporation (2015).

[14] Japan geotechnical society (JGS) Basics and guides to soil tests. Japan geotechnical society: Tokyo, (2002), (Japanese).

[15] Department of Urban Development and Building Construction (DUDBC), Nepal National Building code (NBC) 203:1994 Guidelines for Earthquake Resistant Building Construction: Low Strength Masonry, Department of Urban Development and Building Construction, Kathmandu, (1994).

[16] CEN, EN 1015-11. Methods of test for mortar for masonry-Part 11: Determination of flexural and compressive strength of hardened mortar. European Committee for Standardization, Brussels. (1999). 
[17] Avrami, E., Hubert, G. and Hardy, M. "Terra literature review." An overview of research in earthen architecture conservation: Los Angeles, The Getty Conservation Institute (2008).

[18] Japanese Industry Standard (JIS), Z 2101, Method of test for woods, Tokyo, (2009), (Japanese).

[19] CEN, EN 1052-3, Methods of test for masonry-Part 3: Determination of initial shear strength. Brussels. (2002).

[20] Department of Urban Development and Building Construction, Nepal National Building code. NBC 112:1994 Timber. Department of Urban Development and Building Construction, Kathmandu, (1994).

[21] Endo, Y., Yamaguchi, K., Hanazato, T. and Mishra, C. "Characterisation of mechanical behaviour of masonry composed of fired bricks and earthen mortar." Engineering Failure Analysis (2019): 104280.

[22] CEN, Eurocode 6: Design of masonry structures-Part 1-1: General rules for reinforced and unreinforced masonry structures. European Committee for Standardization, Brussels. (2005).

[23] Kaushik, H.B., Durgesh, C.R. and Sudhir, K.J. "Stress-strain characteristics of clay brick masonry under uniaxial compression." Journal of materials in Civil Engineering 19, no. 9 (2007): 728-739.

[24] TNO Diana, Finite element analysis user's manual-release 10.2'. (2017). 